\title{
Effect of magnetic resonance imaging characteristics on uterine fibroid treatment
}

This article was published in the following Dove Press journal:

Reports in Medical Imaging

\author{
Nguyen Minh Duc \\ Huynh Quang Huy \\ Department of Radiology, Pham Ngoc \\ Thach University of Medicine, Ho Chi \\ Minh City, Vietnam
}

\begin{abstract}
Uterine fibroids are the most common gynecological benign tumors adversely affecting the quality of life of women of a reproductive age. Magnetic resonance imaging (MRI) is efficient at localizing the site of lesions and characterizing uterine fibroids before treatment. Understanding the different characteristics of uterine fibroids on MRI is essential, because it not only enables prompt diagnosis, but also guides the development of suitable therapeutic methods. This pictorial review demonstrates the effect of MRI features on uterine fibroid treatment. Keywords: uterine fibroids, characteristics, magnetic resonance imaging, treatments
\end{abstract}

\section{Introduction}

Uterine fibroids, known as leiomyomas, are the most common gynecological benign tumors affecting premenopausal women. The symptoms include heavy or prolonged menstrual bleeding, pelvic pain/pressure, and reproductive effects, such as subfertility and adverse pregnancy outcomes. The lifetime prevalence of fibroids is $70-80 \%{ }^{1,2}$

Magnetic resonance imaging (MRI) is more sensitive in identifying uterine fibroids than other imaging modalities, and has a high diagnostic performance in leiomyomata imaging. ${ }^{3-5}$

Several surgical or minimally invasive therapeutic modalities are available for treating uterine fibroids, including hysterectomy, laparoscopic surgery, uterine artery embolization (UAE), and high-intensity focused ultrasound (HIFU). MRI is helpful in screening, preoperative planning, treatment guidance, monitoring, and assessment of the treatment response of uterine fibroids to these therapies. ${ }^{6}$ Therefore, in this pictorial review, we demonstrated the effect of MRI features on uterine fibroid treatment.

\section{Imaging method}

The diagnostic pelvic screening procedure was adopted, using a clinical MR system (Ingenia 1.5 Tesla; Philips Healthcare, the Netherlands) to describe uterine fibroid characteristics before treatment. MRI sequences included T2-weighted (T2W) turbo-spin echo parameters (repetition time $(\mathrm{TR}) /$ echo time $(\mathrm{TE})=420 / 160 \mathrm{~ms}$; flip angle $(\mathrm{FA})=90^{\circ}$; resolution $=1.5 \times 1.5 \times 1.5 \mathrm{~mm}$; field of view $(\mathrm{FOV})=250 \mathrm{~mm}^{2} ; 133$ sagittal slices; sensitivity coding [SENSE P[FH];1.8;S[RL]2]) and dynamic contrast-enhanced (DCE)-MRI parameters $\left(\mathrm{TR} / \mathrm{TE}=10 / 4.5 \mathrm{~ms} ; \mathrm{FOV}=240 \mathrm{~mm}^{2} ; \mathrm{FA}=8^{\circ}, 12\right.$ dynamics $=20$ axial slices $)$.
Correspondence: Nguyen Minh Duc Department of Radiology, Pham Ngoc Thach University of Medicine, 86/2 Thanh Thai, Ward 12, District 10, Ho Chi Minh City, Vietnam

Tel +84902886899

Fax +84 38650025

Email bsnguyenminhduc@pnt.edu.vn 


\section{Fibroid types}

Uterine fibroids are commonly described by their position in relation to the surrounding myometrium as intramural, submucosal and subserosal. ${ }^{7}$ Intramural fibroids primarily affect the myometrium and are the most common type; they result in the distortion of the myometrium and uterine cavity (Figure 1A). UAE, HIFU, and abdominal or laparoscopic myomectomy can be used to treat intramural fibroids. ${ }^{4-8}$ Submucosal fibroids project into the endometrial cavity, proliferating in the vicinity of the endometrium (Figure 1B), and are a major cause of abnormal uterine bleeding. ${ }^{4-8}$ Previous studies have demonstrated the effectiveness of UAE and HIFU in treating submucosal fibroids without severe impairment to the endometrium. ${ }^{9} 10$ Subserosal fibroids typically extend outside the uterine wall without distorting the uterine cavity (Figure 1C), and can be treated with laparoscopic surgery. Symptoms of typical subserosal fibroids are less severe than those of other fibroid types. ${ }^{4-8}$

Pedunculated submucosal or subserosal fibroids develop on stalks outward from the uterine surface or into the uterine cavity (Figure 2). Pain is a common symptom, due to the pressure caused by pedunculated subserosal fibroids on the nearby structures. Pedunculated submucosal fibroids cause excessive blood loss during menstrual cycles. ${ }^{4-8}$ UAE has been adopted as a substitute minimally invasive treatment for pedunculated subserosal uterine fibroids without severe complications. ${ }^{11,12} \mathrm{HIFU}$ was also proven as being safe and effective for pedunculated subserosal fibroids not expelled into the abdominal cavity after ablation. ${ }^{13}$

Uterine fibroids can be classified according to their positions: anterior wall, fundus, posterior wall, and cervix. ${ }^{14}$ In HIFU treatment of uterine fibroids, tumors on the anterior wall or fundus can benefit from the heat accumulation during ablation (Figure $3 \mathrm{~A}$ and B). ${ }^{15,16}$ The distance between uterine fibroids on the posterior wall of the retroverted uterus and the
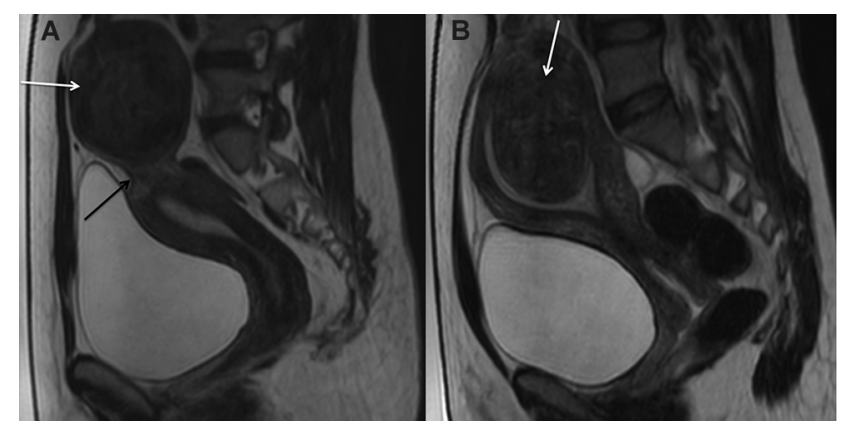

Figure 2 Sagittal T2-weighted MRIs show (A) the pedunculated subserosal uterine fibroid projecting outward the uterus (white arrow) with a small stalk linked to the fundus of uterus (black arrow); and (B) the pedunculated submucosal uterine fibroid projecting inward the uterine cavity (white arrow).

Abbreviation: MRIs, magnetic resonance images.

skin surface is larger than that between uterine fibroids on the anterior wall of the anteverted uterus and skin surface; this is negatively correlated to the ablation efficacy (Figure 3C). ${ }^{17,18}$ Cervical uterine fibroids interfering with cervical dilatation during childbirth are strong candidates for vaginal myomectomy (Figure 3D). ${ }^{19}$

\section{Fibroid number}

Uterine fibroids can be divided into single fibroid, multiple fibroids (Figure 4), and uterine leiomyomatosis (Figure 5). ${ }^{4-8}$ It is crucial to avoid laparoscopic myomectomies in patients who have more than five fibroids, as the procedure is excessively time-consuming. ${ }^{12,20,21}$ Studies have demonstrated that the mean total laparoscopic operating time in patients with a single uterine fibroid is significantly shorter than that in patients with $\geq 2$ uterine fibroids. ${ }^{20,21}$ Furthermore, patients with $\geq 5$ have an increased risk of technical failure of HIFU treatment (Table 1). ${ }^{17,18}$

Uterine leiomyomatosis is a specific condition, manifesting in innumerable small uterine fibroids, which cause a symmetrical enlargement of the uterus. Gonadotropin-releasing

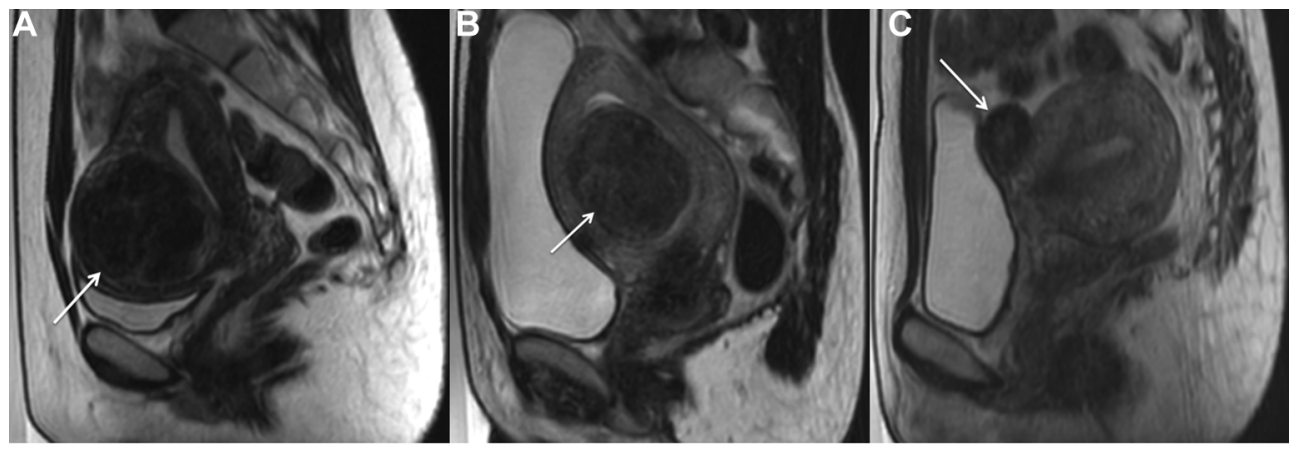

Figure I Sagittal T2-weighted MRIs show (A) the intramural uterine fibroid inside the myometrium (white arrow); (B) the submucosal uterine fibroid projecting completely into uterine cavity (white arrow); and (C) the subserosal uterine fibroid projecting outward the uterus (white arrow).

Abbreviation: MRIs, magnetic resonance images. 


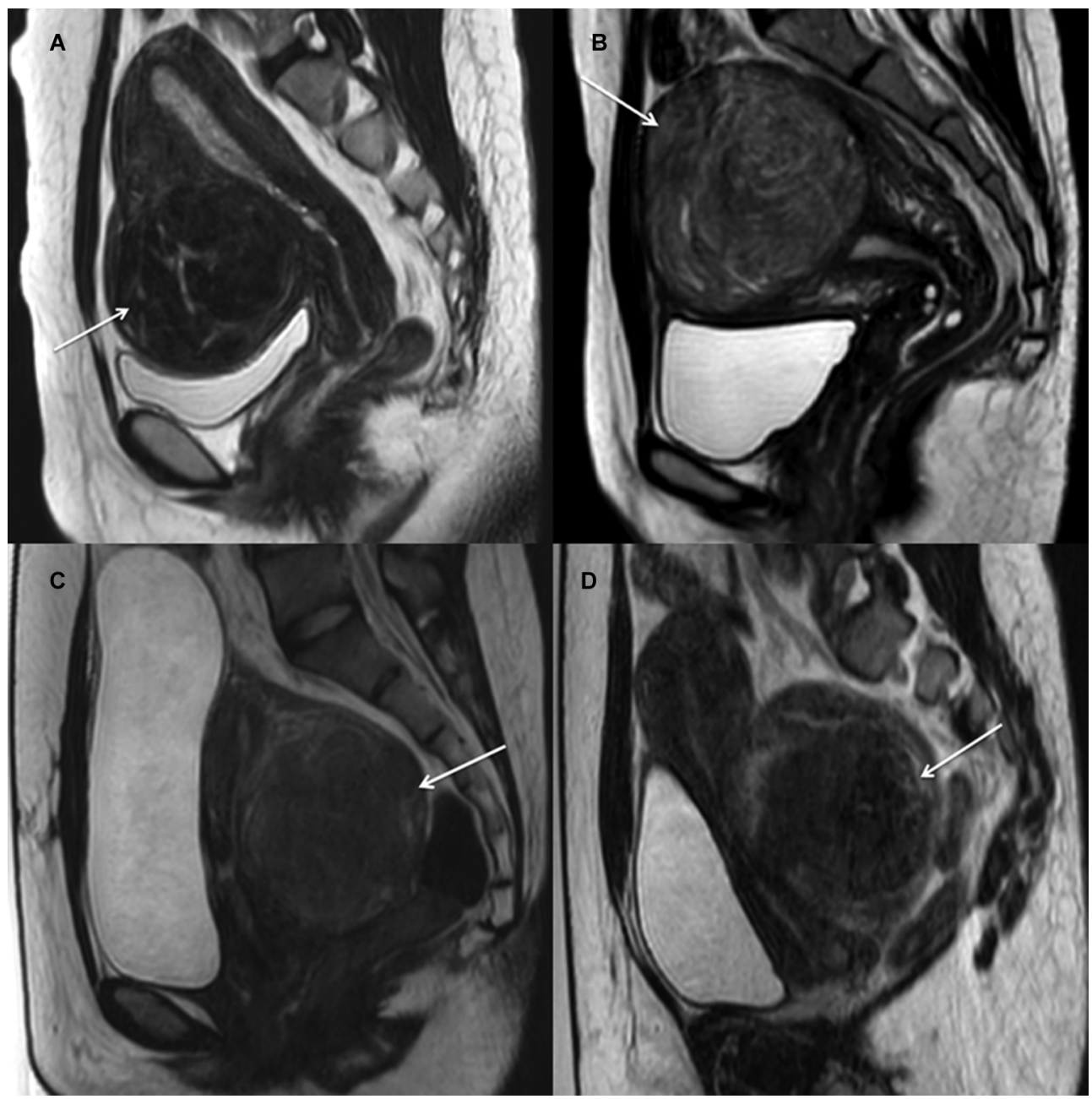

Figure 3 Sagittal T2-weighted MRIs show (A) uterine fibroid on the anterior wall of the uterus (white arrow); (B) the uterine fibroid on fundus of uterus (white arrow); (C) the uterine fibroid on the posterior wall of the uterus (white arrow); and (D) the uterine fibroid on cervical area of the uterus (white arrow).

Abbreviation: MRIs, magnetic resonance images.

hormone $(\mathrm{GnRH})$ agonists are prescribed as internal medication to preserve the uterus. Alternatively, hysterectomies are performed as a radical treatment for this distinctive disease. ${ }^{4,22}$

\section{Fibroid size}

The size of uterine fibroids varies from $1 \mathrm{~cm}$ to several centimeters (Figure 6). Indications for myomectomy via laparoscopic surgery are rapid uterine fibroid growth, heavy abnormal uterine bleeding, severe pain in the pelvis, infertility, and a uterine fibroid diameter $\geq 6 \mathrm{~cm}$. In laparoscopic surgery, the maximal diameter of uterine fibroids should not exceed $10 \mathrm{~cm}$, to avoid blood loss and a time-consuming procedure. ${ }^{6,23}$ Furthermore, uterine leiomyomatosis with a uterus size resembling that at 12-14 weeks of pregnancy or rapid development of uterine fibroids during menopause are reasonable indications for hysterectomy. ${ }^{6,23,24}$ In evidencebased analysis, the maximal diameter of uterine fibroids indicating HIFU is $10 \mathrm{~cm}$, because it requires patients to adopt the prone position for $\geq 3 \mathrm{~h} .{ }^{17,18}$ Patients with uterine fibroids of $>10 \mathrm{~cm}$ are likely to experience tumor lysis syndrome after HIFU treatment; ${ }^{25}$ however, in a previous UAE study, no significant difference existed in the overall complication rate between patients with uterine fibroids of $\geq 10 \mathrm{~cm}$ (in diameter) and those with uterine fibroids of $<10$ $\mathrm{cm}$ (Table 2). ${ }^{26}$ Nevertheless, it is worth noting that, at the 3-month follow-up after UAE treatment, patients with smaller uterine fibroids exhibited a greater volume reduction than those with larger uterine fibroids..$^{9,27}$

\section{T2W imaging}

The correlation between the T2 signal intensity (SI) of uterine fibroids and histopathology proves that "typical uterine" fibroids composed predominantly of fibroma manifest a low and homogeneous SI, degenerative uterine fibroids manifest 


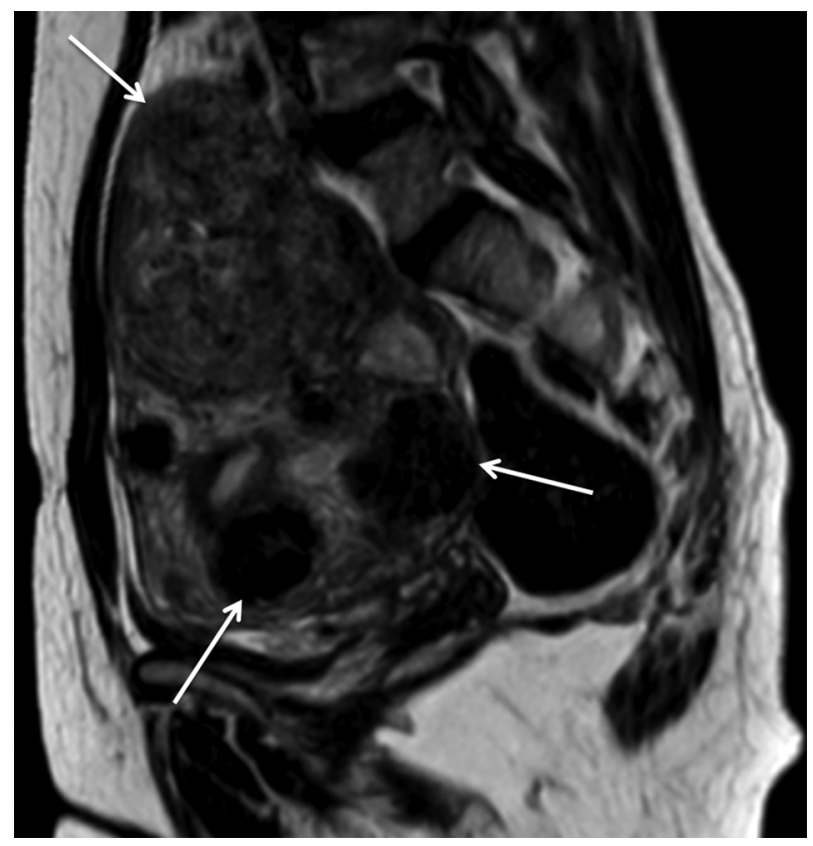

Figure 4 Sagittal T2-weighted MRI shows multiple uterine fibroids affecting anterior, posterior, and fundus of uterus (white arrow).

Abbreviation: MRI, magnetic resonance image.

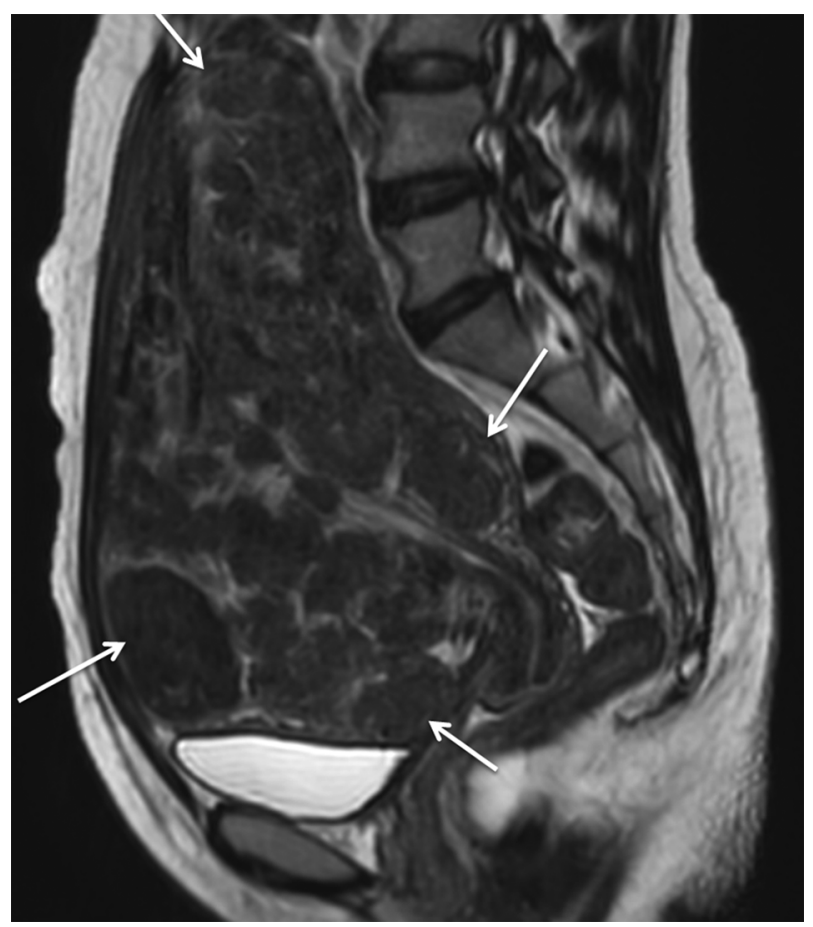

Figure 5 Sagittal T2-weighted MRI shows uterine leiomyomatosis with the whole uterus transformed to numerous small fibroids (white arrow).

Abbreviation: MRI, magnetic resonance image.

Table I Fibroid number and treatment options

\begin{tabular}{llll}
\hline Fibroid number & Laparoscopic surgery & UAE & HIFU \\
\hline$<5$ & + & + & + \\
$\geq 5$ & - & + & - \\
\hline
\end{tabular}

Abbreviations: UAE, uterine artery embolization; HIFU, high-intensity focused ultrasound.

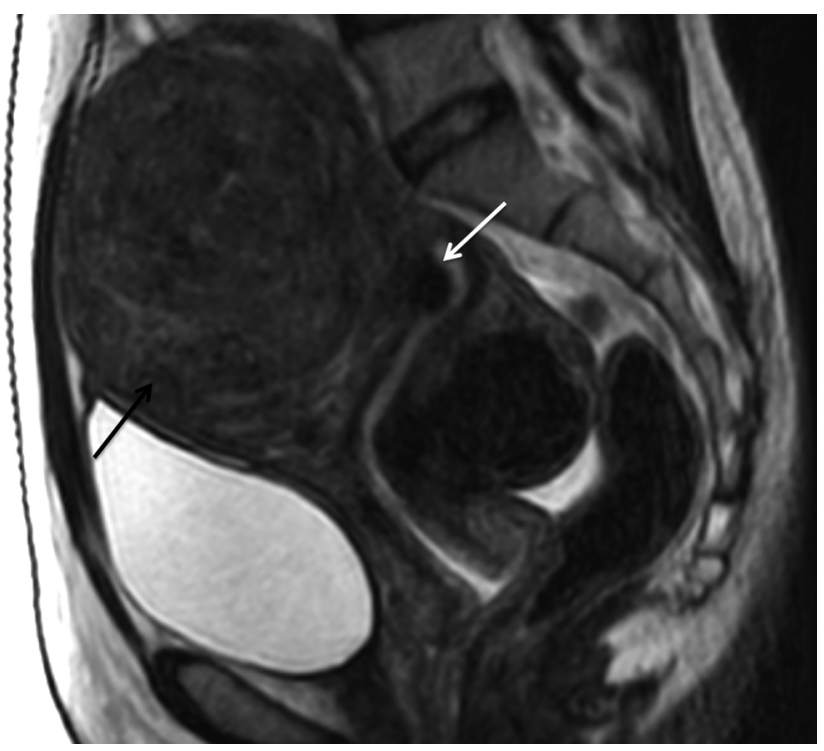

Figure 6 Sagittal T2-weighted MRI shows a comparison in size of one small submucosal uterine fibroid (white arrow) and one big subserosal uterine fibroid (black arrow).

Abbreviation: MRI, magnetic resonance image.

Table 2 Fibroid size and treatment options

\begin{tabular}{llll}
\hline Fibroid size & Laparoscopic surgery & UAE & HIFU \\
\hline$<10 \mathrm{~cm}$ & + & + & + \\
$\geq 10 \mathrm{~cm}$ & - & + & - \\
\hline
\end{tabular}

Abbreviations: UAE, uterine artery embolization; HIFU, high-intensity focused ultrasound.

a heterogeneous and variable SI, and cellular uterine fibroids with a higher smooth muscle content relative to connective fibrous tissue manifest a high and homogeneous SI. ${ }^{28}$ Among these types, cellular uterine fibroids are the most challenging to be adapted to therapeutic treatment. ${ }^{29}$

In a previous HIFU study, T2 SI-based classification was used as the primary MRI classification parameter for determining patient suitability by classifying fibroids into one of three types by visual inspection: type I (SI lower than or equal to that of skeletal muscles; Figure 7A), type II (SI lower than that of the myometrium but higher than that of skeletal muscles; Figure 7B), or type III (SI higher than that of the myometrium; Figure $7 \mathrm{C}) \cdot{ }^{30}$ They concluded that type I uterine fibroids were suitable for HIFU treatment because of greater improvement in clinical symptoms and volume reduction post-treatment. However, type III fibroids were unsuitable for HIFU treatment because of worse outcomes. ${ }^{30}$ Furthermore, in previous UAE studies, patients with high-T2 SI uterine fibroids obtained greater volume reduction during the follow-up period (Table 3). ${ }^{31,32}$

The high ratio of the T2 SI of uterine fibroids to that of skeletal muscle was a negatively effective parameter, 


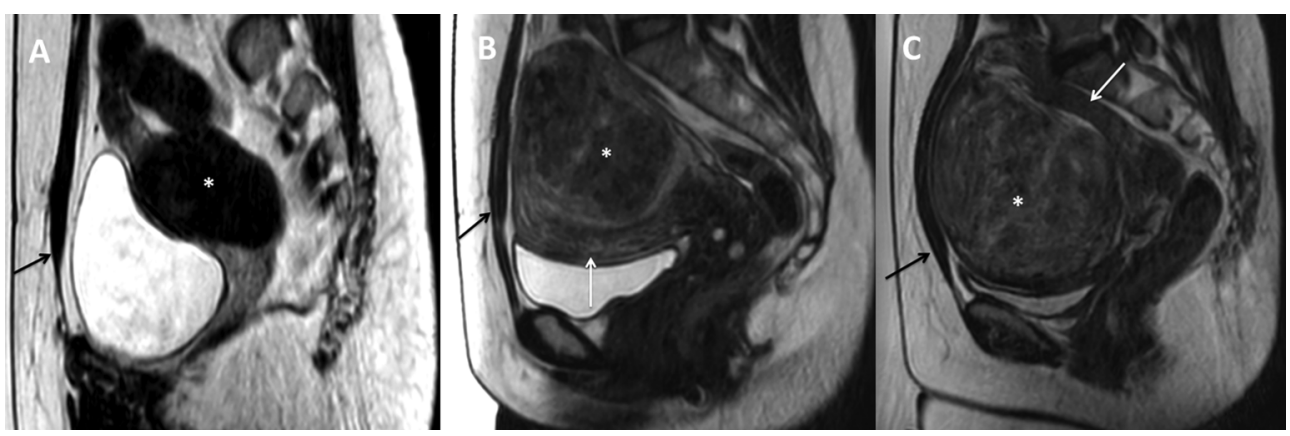

Figure 7 Sagittal T2-weighted MRIs show uterine fibroid (white asterisk) of (A) type I with the signal intensity of uterine fibroid equal to abdominis rectus muscle (black arrow); (B) type Il with the signal intensity of uterine fibroid brighter than abdominis rectus muscle (black arrow) but darker than myometrium (white arrow); and (C) type III with the signal intensity of uterine fibroid brighter than both abdominis rectus muscle (black arrow) and myometrium (white arrow).

Abbreviation: MRIs, magnetic resonance images.

Table 3 T2 classification and treatment options

\begin{tabular}{lll}
\hline T2 classification & UAE & HIFU \\
\hline Type I & - & + \\
Type II & + & + \\
Type III & + & - \\
\hline
\end{tabular}

Abbreviations: UAE, uterine artery embolization; HIFU, high-intensity focused ultrasound.

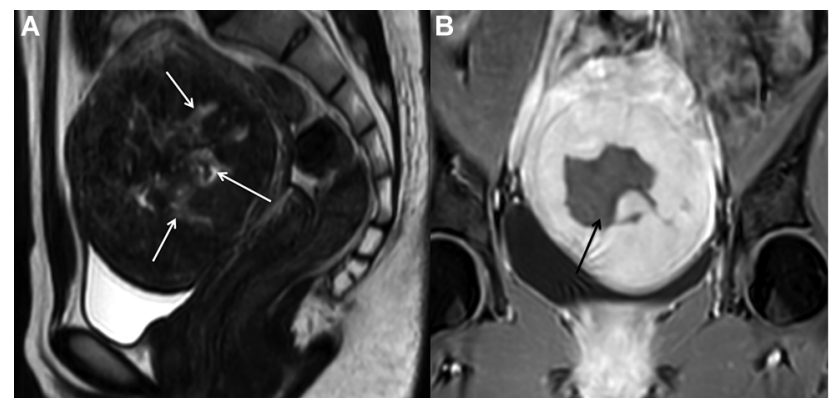

Figure 8 Sagittal T2-weighted MRI (A) shows the uterine fibroid with hyperintense area inside the tumor (white arrow). Axial contrast enhancement TI-weighted MRI (B) shows the central non-enhanced uterine fibroid corresponding to the hyperintense area of $\mathrm{T} 2 \mathrm{~W}$ image (black arrow).

Abbreviations: MRIs, magnetic resonance images; T2W, T2-weighted.

influencing ablation quality and efficiency. ${ }^{33}$ Meanwhile, this high ratio was positively correlated to the outcome of UAE. ${ }^{34}$

\section{TI-perfusion imaging}

The water produced by degeneration and vascularity inside tumors can cause high SI on T2W images (Figures 8 and 9). Strong vascularity in uterine fibroids during HIFU ablation causes insufficient thermal dose in the targeted volume due to heat dissipation. ${ }^{35-37}$

Previous case reports suggested that high-T2 SI fibroids that exhibit delayed enhancement in DCE MRIs can be treated successfully if the hyperintensity is caused by high fluid content rather than high vascularity. ${ }^{35,36}$ This proves that T2 SI-based classification is limited in differentiating high

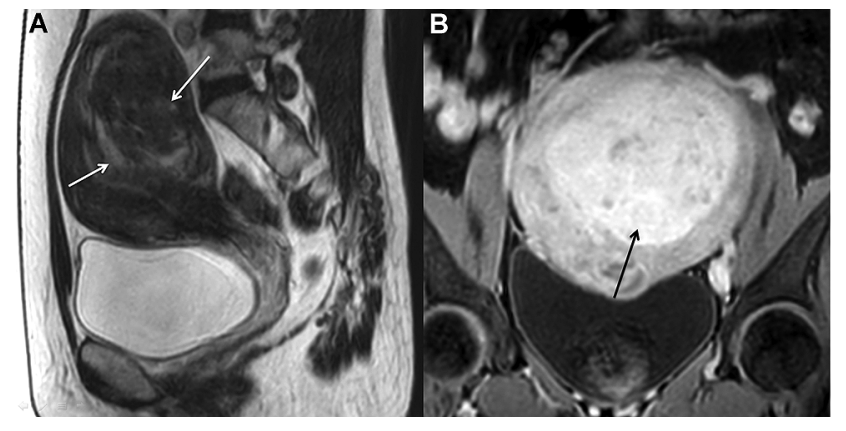

Figure 9 Sagittal T2-weighted MRI (A) shows the uterine fibroid with hyperintense area inside the tumor (white arrow). Axial contrast enhancement TI-weighted MRI shows (B) the full-enhanced uterine fibroid (black arrow).

Abbreviation: MRI, magnetic resonance image.

SI between degeneration and vascularity. To overcome this problem, T1-perfusion imaging is a robust and supplementary technique for assessing the vascularity and perfusion of tumors. ${ }^{35-37}$

A new classification method was recently introduced based on comparisons of the MR T1 perfusion-based time-SI curves of fibroid tissue and the myometrium in screening MRI (Group A if the time-SI curve of fibroid tissue is lower than that of the myometrium [Figure 10] and Group B if the timeSI curve of fibroid tissue is equal to or higher than that of the myometrium [Figure 11]). The results of bivariate analysis in their study revealed a very strong correlation between $\mathrm{T} 1$ perfusion-based classification and immediate NPV ratio. The preliminary findings of the therapeutic efficacy at 6-months follow-up also showed that there was a significant correlation between immediate nonperfused volume (NPV) ratio and transformed symptom severe score improvement ratios and fibroid volume reduction ratios. ${ }^{37}$ It is stated that strong perfusion uterine fibroids were better adapted to UAE than weak perfusion uterine fibroids (Table 4)..$^{31,32,34}$

Other medical interventions, such as GnRH agonist treatment, are used primarily as preoperative therapy for reducing 


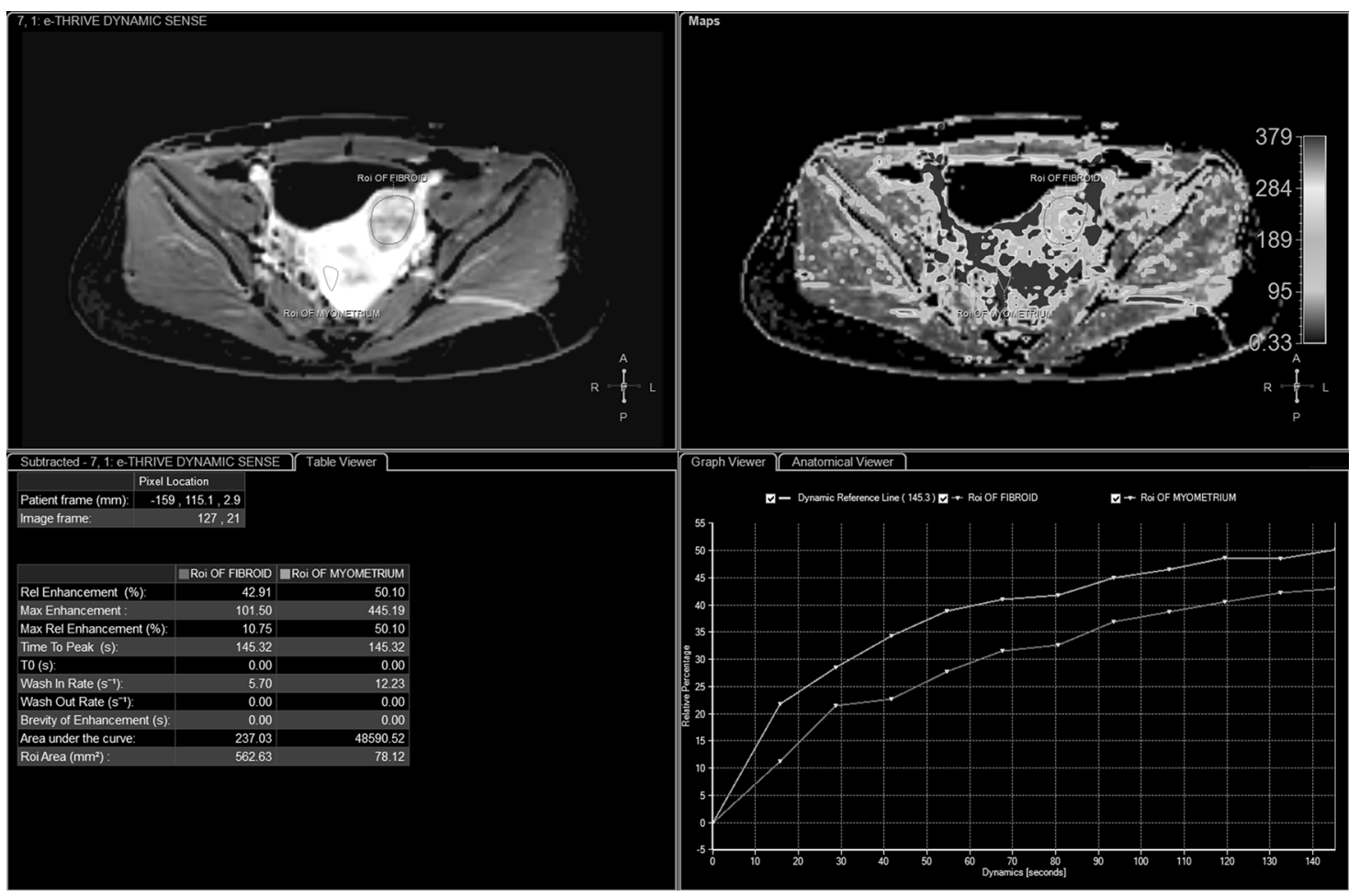

Figure 10 Classification of uterine fibroid on the basis of MR TI perfusion-based time-SI curves of uterine fibroid and the myometrium. A semi-quantitative perfusion MRI was analyzed by drawing a ROI within the area of the uterine fibroid and the myometrium on one of the perfusion MRIs (left upper, left section). The software automatically generated maps for each perfusion parameter (right upper, right section) and semi-quantitative perfusion MRI parameters (left lower, left section). The time-SI curve of the fibroid is lower than that of the myometrium.

Abbreviations: MR, magnetic resonance; MRI, magnetic resonance image; ROI, region of interest; Sl, signal intensity.
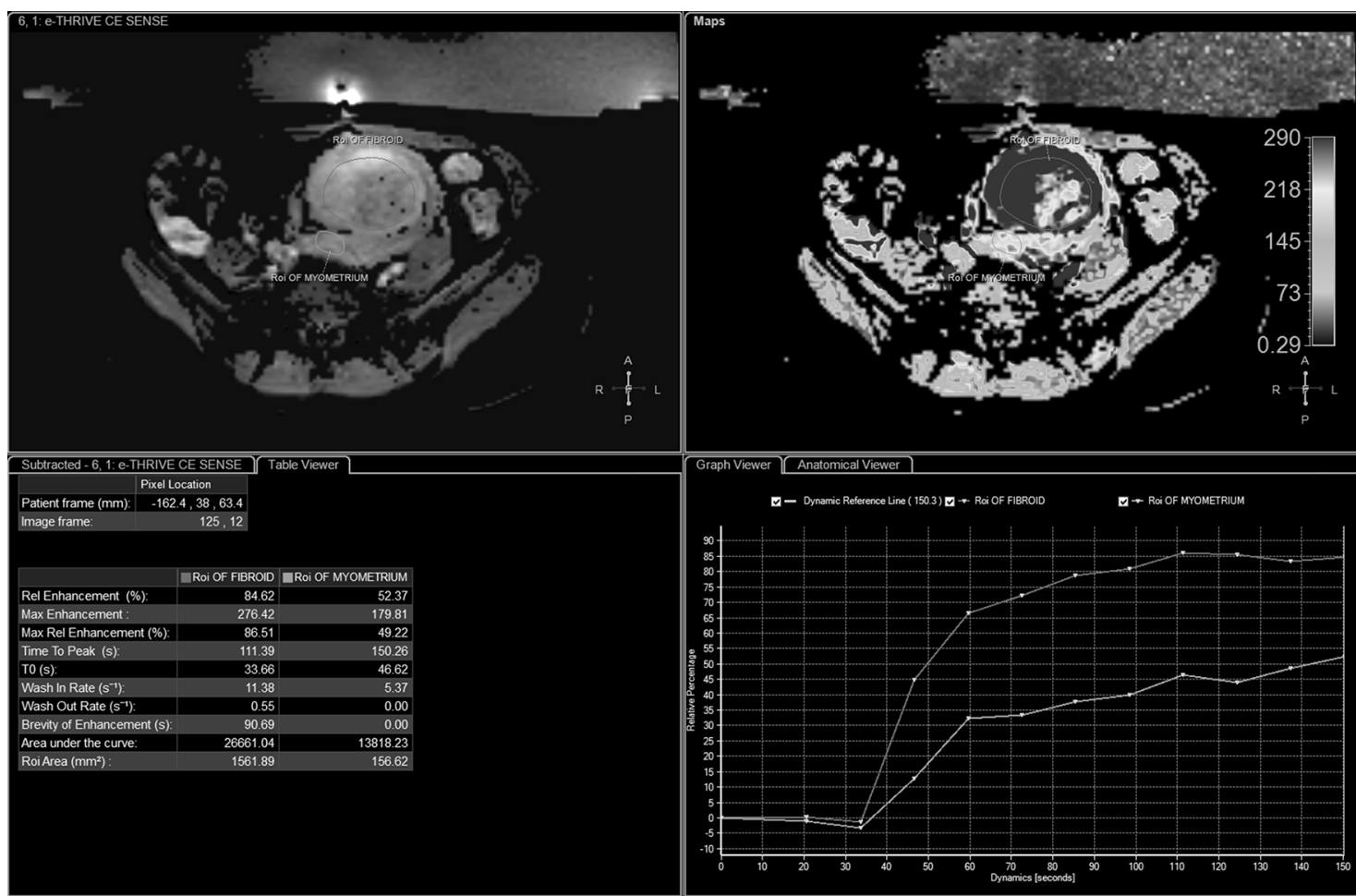

Figure I I Classification of uterine fibroid on the basis of MR TI perfusion-based time-SI curves of uterine fibroid and the myometrium. A semi-quantitative perfusion MRI was analyzed by drawing a ROI within the area of the uterine fibroid and the myometrium on one of the perfusion MRIs (left upper, left section). The software automatically generated maps for each perfusion parameter (right upper, right section) and semi-quantitative perfusion MRI parameters (left lower, left section). The time-SI curve of the fibroid is higher than that of the myometrium.

Abbreviations: MR, magnetic resonance; MRI, magnetic resonance image; ROI, region of interest; Sl, signal intensity. 
Table $4 \mathrm{TI}$ perfusion classification and treatment options

\begin{tabular}{lll}
\hline TI perfusion classification & UAE & HIFU \\
\hline Group A & - & + \\
Group B & + & - \\
\hline
\end{tabular}

Abbreviations: UAE, uterine artery embolization; HIFU, high-intensity focused ultrasound.

uterine fibroid vascularity and volume. T1-perfusion imaging is also sensitive to uterine fibroid vascular changes caused by GnRH agonist treatment. ${ }^{38-40}$

\section{Conclusion}

MRI can facilitate preoperative treatment planning for myomectomy, HIFU, UAE, and hysterectomy by enabling a clear detection and localization of individual uterine fibroids. Based on the location, size, number, T2 classification, and T1-perfusion classification of uterine fibroids, clinicians could clearly identify uterine fibroid characteristics and select the optimal and most appropriate treatment method for achieving better outcomes.

\section{Acknowledgments}

The authors state that this work has not received any funding.

\section{Disclosure}

The authors report no conflicts of interest in this work.

\section{References}

1. Stewart EA. Clinical practice. Uterine fibroids. $N$ Engl $J$ Med. 2015;372(17):1646-1655.

2. Bulun SE. Uterine fibroids. N Engl J Med. 2013;369(14):1344-1355.

3. Vilos GA, Allaire C, Laberge PY, et al. The management of uterine leiomyomas. J Obstet Gynaecol Can. 2015;37(2):157-178.

4. Murase E, Siegelman ES, Outwater EK, Perez-Jaffe LA, Tureck RW. Uterine leiomyomas: histopathologic features, MR imaging findings, differential diagnosis, and treatment. Radiographics. 1999;19(5):1179-1197.

5. Dudiak CM, Turner DA, Patel SK, Archie JT, Silver B, Norusis M. Uterine leiomyomas in the infertile patient: preoperative localization with MR imaging versus US and hysterosalpingography. Radiology. 1988;167(3):627-630.

6. Khan AT, Shehmar M, Gupta JK. Uterine fibroids: current perspectives. Int $J$ Womens Health. 2014;6:95-114.

7. Casini ML, Rossi F, Agostini R, Unfer V. Effects of the position of fibroids on fertility. Gynecol Endocrinol. 2006;22(2):106-109.

8. Wilde S, Scott-Barrett S. Radiological appearances of uterine fibroids. Indian J Radiol Imaging. 2009;19(3):222-231.

9. Spies JB, Roth AR, Jha RC, et al. Leiomyomata treated with uterine artery embolization: factors associated with successful symptom and imaging outcome. Radiology. 2002;222(1):45-52.

10. Kim YS, Kim TJ, Lim HK, et al. Preservation of the endometrial enhancement after magnetic resonance imaging-guided high-intensity focused ultrasound ablation of submucosal uterine fibroids. Eur Radiol. 2017;27(9):3956-3965.

11. Katsumori T, Akazawa K, Mihara T. Uterine artery embolization for pedunculated subserosal fibroids. AJR Am J Roentgenol. 2005;184(2): 399-402.
12. Smeets AJ, Nijenhuis RJ, Boekkooi PF, et al. Safety and effectiveness of uterine artery embolization in patients with pedunculated fibroids. J Vasc Interv Radiol. 2009;20(9):1172-1175.

13. Park H, Yoon SW, Kim KA, Jung Kim D, Jung SG. Magnetic resonance imaging-guided focused ultrasound treatment of pedunculated subserosal uterine fibroids: a preliminary report. J Vasc Interv Radiol. 2012;23(12):1589-1593.

14. Mettler L, Audebert A, Lehmann-Willenbrock E, Schive-Peterhansl K, Jacobs VR. A randomized, prospective, controlled, multicenter clinical trial of a sprayable, site-specific adhesion barrier system in patients undergoing myomectomy. Fertil Steril. 2004;82(2):398-404.

15. Kim YS, Kim JH, Rhim H, et al. Volumetric MR guided high-intensity focused ultrasound ablation with a one-layer strategy to treat large uterine fibroids: initial clinical outcomes. Radiology. 2012;263(2):600-609.

16. Hou R, Wang L, Li S, et al. Pilot study: safety and effectiveness of simple ultrasound-guided high-intensity focused ultrasound ablating uterine leiomyoma with a diameter greater than $10 \mathrm{~cm} . \mathrm{Br} J$ Radiol. 2018;91(1082):20160950

17. Froling V, Kroncke TJ, Schreiter NF, et al. Technical eligibility for treatment of magnetic resonance-guided focused ultrasound surgery. Cardiovasc Intervent Radiol. 2014;37(2):445-450.

18. Pron G. Magnetic resonance-guided high-intensity focused ultrasound (MRgHIFU) treatment of symptomatic uterine fibroids: an evidencebased analysis. Ont Health Technol Assess Ser. 2015;15(4):1-86.

19. Obara M, Hatakeyama Y, Shimizu Y. Vaginal myomectomy for semipedunculated cervical myoma during pregnancy. Am J Perinatol Rep. 2014;4:37-40

20. Hadisaputra W, Pratama AA. How to manage multiple fibroids in reproductive laparoscopic surgery. Gynecol Minim Invas Ther. 2013;2:110-113.

21. Mettler L, Schollmeyer T, Tinelli A, Malvasi A, Alkatout I. Complications of uterine fibroids and their management, surgical management of fibroids, laparoscopy and hysteroscopy versus hysterectomy, haemorrhage, adhesions, and complications. Obstet Gynecol Int. 2012;2012:791248.

22. Fedele L, Bianchi S, Zanconato G, Carinelli S, Berlanda N. Conservative treatment of diffuse uterine leiomyomatosis. Fertil Steril. 2004;82(2):450-453.

23. Duhan N. Current and emerging treatments for uterine myoma-an update. Int $J$ Womens Health. 2011;3:231-241.

24. Coskun A, Ozdemir O, Vardar MA, Kiran G, Arikan D, Ersoz C. A case with diffuse uterine leiomyomatosis and review of the literature. Clin Exp Obstet Gynecol. 2008;35(3):227-230.

25. Park JH, Yang IM, Kim YH, Yu SJ, Lee JS, Kim DH. High intensity focused ultrasound treatment-induced tumor lysis syndrome in uterine myoma patient. Soonchunhyang Med Sci. 2015;21(2):99-101.

26. Katsumori T, Nakajima K, Mihara T. Is a large fibroid a high-risk factor for uterine artery embolization? AJR Am J Roentgenol. 2003;181(5):1309-1314.

27. Spies JB, Ascher SA, Roth AR, Kim J, Levy EB, Gomez-Jorge J. Uterine artery embolization for leiomyomata. Obstet Gynecol. 2001;98(1):29-34.

28. Swe TT, Onitsuka H, Kawamoto K, Ueyama T, Tsuruchi N, Masuda $\mathrm{K}$. Uterine leiomyoma: correlation between signal intensity on magnetic resonance imaging and pathologic characteristics. Radiat Med. 1992;10(6):235-242.

29. Oguchi O, Mori A, Kobayashi Y, Horiuchi A, Nikaido T, Fujii S. Prediction of histopathologic features and proliferative activity of uterine leiomyoma by magnetic resonance imaging prior to GnRH analogue therapy: correlation between T2-weighted images and effect of GnRH analogue. J Obstet Gynaecol. 1995;21(2):107-117.

30. Funaki K, Fukunishi H, Funaki T, Sawada K, Kaji Y, Maruo T. Magnetic resonance-guided focused ultrasound surgery for uterine fibroids: relationship between the therapeutic effects and signal intensity of preexisting T2 weighted magnetic resonance images. Am J Obstet Gynecol. 2007;196(2):184. 
31. Chang S, Kim MD, Lee M, et al. Uterine artery embolization for symptomatic fibroids with high signal intensity on T2-weighted MR imaging. Korean J Radiol. 2012;13(5):618-624.

32. deSouza NM, Williams AD. Uterine arterial embolization for leiomyomas: perfusion and volume changes at MR imaging and relation to clinical outcome. Radiology. 2002;222(2):367-374.

33. Kim YS, Lim HK, Park MJ, et al. Screening magnetic resonance imaging-based prediction model for assessing immediate therapeutic response to magnetic resonance imaging-guided high-intensity focused ultrasound ablation of uterine fibroids. Invest Radiol. 2016;51(1):15-24.

34. Zlotnik E, Lorenzo Messina Md, Nasser F, et al. Predictive factors for pelvic magnetic resonance in response to arterial embolization of a uterine leiomyoma. Clinics. 2014;69(3):185-189.

35. Yoon SW, Lee C, Kim KA, Kim SH. Contrastenhanced dynamic MR imaging of uterine fibroids as a potential predictor of patient eligibility for MR guided focused ultrasound (MRgFUS) treatment for symptomatic uterine fibroids. Obstet Gynecol Int. 2010;2010:834275.
36. Liu J, Keserci B, Yang X, et al. Volume transfer constant (K(trans)) maps from dynamic contrast enhanced MRI as potential guidance for MR-guided high intensity focused ultrasound treatment of hypervascular uterine fibroids. Magn Reson Imaging. 2014;32(9): $1156-1161$.

37. Keserci B, Duc NM. The role of $\mathrm{T} 1$ perfusion-based classification in magnetic resonance-guided high-intensity focused ultrasound ablation of uterine fibroids. Eur Radiol. 2017;27(12):5299-5308.

38. Zaher S, Gedroyc WM, Regan L. Patient suitability for magnetic resonance guided focused ultrasound surgery of uterine fibroids. Eur J Obstet Gynecol Reprod Biol. 2009;143(2):98-102.

39. Munro KI, Thrippleton MJ, Williams AR, et al. Quantitative serial MRI of the treated fibroid uterus. PLoS One. 2014;9(3):e89809.

40. Deligdisch L, Hirschmann S, Altchek A. Pathologic changes in gonadotropin releasing hormone agonist analogue treated uterine leiomyomata. Fertil Steril. 1997;67(5):837-841.

\section{Publish your work in this journal}

Reports in Medical Imaging is an international, peer-reviewed, open access journal publishing original research, reports, reviews and commentaries on all areas of medical imaging. The manuscript management system is completely online and includes a very quick and fair peer-review system, which is all easy to use.

\section{Dovepress}

Visit http://www.dovepress.com/testimonials.php to read real quotes from published authors. 